\title{
The toughness of epoxy-poly(butylene terephthalate) blends
}

\author{
M. E. NICHOLS, R. E. ROBERTSON* \\ Department of Materials Science and Engineering, The University of Michigan, Ann Arbor, \\ MI 48109-2136, USA
}

\begin{abstract}
Blends containing $5 \%$ poly (butylene terephthalate) (PBT) in an anhydride-cured epoxy with three different PBT morphologies were studied. The three morphologies were a dispersion of spherulites, a structureless gel and a gel with spherulites. The average fracture toughnesses, $K_{\mathrm{lc}}$, and fracture energies, $G_{\mathrm{lc}}$, for those morphologies were $0.83,2.3$ and $1.8 \mathrm{MPa} \mathrm{m}^{1 / 2}$ and 240,2000 and $1150 \mathrm{~J} \mathrm{~m}^{-2}$, respectively. These values should be compared with the values of $0.72 \mathrm{MPa} \mathrm{m}^{1 / 2}$ and $180 \mathrm{~J} \mathrm{~m}^{-2}$, respectively, for the cured epoxy without PBT. The elastic moduli and yield strengths in compression for all three blend morphologies remained essentially unchanged from those of the cured epoxy without PBT, namely, 2.9 GPa for the modulus and $115 \mathrm{MPa}$ for the yield strength. The fracture surfaces of the cured spherulitic dispersion blends indicate the absorption of fracture energy by crack bifurcation induced by the spherulites. The fracture surfaces of the cured structureless gel blends indicate that fracture energy was absorbed by matrix and PBT plastic deformation and by spontaneous crack bifurcation. But phase transformation of the PBT and anelastic strain of the matrix below the fracture surfaces may account for most of the large fracture energy of the cured structureless gel blends.
\end{abstract}

\section{Introduction}

The widespread use of epoxies as adhesives and as matrices in fibre composites is a result of their outstanding combination of physical properties including: high strength, high modulus, good solvent and temperature resistance and good processability. The major weakness of these materials is their brittleness or low fracture toughness, especially in the presence of sharp cracks. Combatting this low toughness has been a major research effort during the past 20 years [1-8]. Much progress has been made, particularly in toughening epoxies which display some inherent ductility. Blending with CTBN (carboxyl-terminated butadienenitride) rubber can increase the fracture energy of these epoxies by an order of magnitude or more. During the fracture process, the rubber particles ahead of the crack tip are thought to cavitate and thereby relieve the triaxial stress state ahead of the crack tip [3, 5-7]. This, in turn, promotes shear yielding in the surrounding epoxy, leading to an enlarged plastic zone in which a large amount of energy is absorbed. The addition of rubber, however, decreases the modulus and yield strength of the epoxy [5]. Additionally, the toughenability of epoxies is inversely related to their cross-link density $[7,9,10]$. Thus, those epoxies with high crosslink densities and glass-transition temperatures are inherently more difficult to toughen by blending with rubber. Therefore, other methods of toughening high $T_{\mathrm{g}}$ epoxies have been sought.
The use of thermoplastic particles as second-phase toughening agents in epoxies has been explored more recently [11-22]. In most cases only modest improvements in the fracture energy have been reported. The greatest success has been found in those systems where functionalized oligomers of various engineering polymers have been prepared and blended with the epoxies $[18,19]$. The oligomers are synthesized to contain various end groups to promote adhesion to the surrounding epoxy matrix. At low fractions of the thermoplastic, these blends contain small thermoplastic spheres surrounded by an essentially pure epoxy matrix. The greatest improvements in toughness, however, are only obtained at high fractions of the thermoplastic, where the thermoplastic becomes the continuous phase [19]. Often the thermoplastic is dissolved in the epoxy to aid in processing. The thermoplastic phase separates from the epoxy during curing; this process is not well-understood. Because most of the polymers blended with epoxy are amorphous or weakly crystallizable, the morphology is determined solely by the phase-separation process. Blending a highly crystallizable polymer with an epoxy, on the other hand, would offer a wider degree of morphological control and the ability to tailor the morphology to optimize certain physical properties. Indications have been previously obtained that control of the toughening by control of the morphology was possible with the highly crystallizable polymer, poly(butylene

*Author to whom correspondence should be addressed. 
terephthalate) (PBT) $[21,22]$. But little work other than this has been reported on the effect of the secondphase morphology on the toughness of thermoplastic-epoxy blends, aside from that of volume fraction. In this report, a systematic exploration of the relationship between the thermal history, the morphology and the mechanical properties of PBT-epoxy blends is described.

\section{Experimental procedure}

\subsection{Materiais}

Poly(butylene terephthalate) (PBT) was obtained from the Aldrich Chemical Company in the form of small pellets. The molecular weight was determined as 37800 by the dilute solution viscosity in a $60: 40$ phenol:tetrachloroethane mixture. Mark-Howink constants of $a=0.871$ and $K=1.17 \times 10^{-2} \mathrm{cc} \mathrm{g}^{-1}$ were used to determine the molecular weight [23]. The epoxy which was used was the common diglycidyl ether of bisphenol A (DGEBA) epoxy that is sold under the trade name Epon 828 by Shell Chemical Company. This epoxy has on average 1.2 bisphenol $\mathrm{A}$ groups per molecule. The curing agent used was methylnorbornene-2,3-dicarboxylic anhydride, which is also known as NADIC methyl anhydride (NMA). 2Ethyl-4-methyl imidazole (EMI-24) was used as an accelerator to speed curing. Both the curing agent and the accelerator were obtained from Aldrich Chemical Company. Ninety parts of the curing agent (by weight) were added for every 100 parts of the epoxy. The accelerator was added in a concentration of $0.1 \%$. All the blends reported here contained 5\% PBT by weight. The chemical structures of the materials are shown in Fig. 1.

\subsection{Preparation}

To obtain a fine dispersion of PBT in the epoxy, pellets of PBT were dissolved in liquid epoxy at

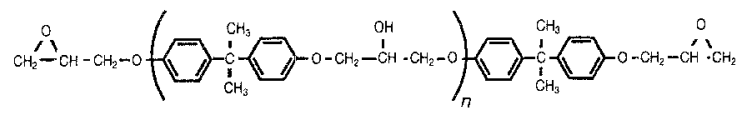

(a)

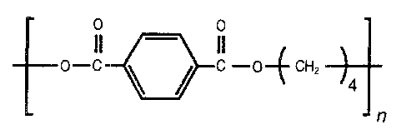

(b)

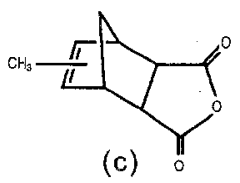

Figure 1 Chemical structures of: (a) DGEBA epoxy, (b) PBT and (c) the curing agent. $220^{\circ} \mathrm{C}$. After complete dissolution, typically occurring within $1 \mathrm{~h}$, the mixture of PBT and the epoxy was cooled to room temperature. On cooling, small PBT particles formed by crystallization from the solution. Two different processing methods were subsequently used to prepare cured plaques with specific morphologies.

The first method involved reheating the mixture to $220^{\circ} \mathrm{C}$ to redissolve the PBT. The solution was then cooled to $155^{\circ} \mathrm{C}$ and held for $1 \mathrm{~h}$, while the PBT crystallized. Most of the crystallization occurred in the first few minutes. The temperatures and times for the crystallization were determined from an earlier study of the solution/crystallization behaviour of the epoxyPBT system [24]. The mixture was subsequently cooled to room temperature, where the curing agent and the acceleration were added. This mixture was degassed under vacuum and poured into a mould to make $6 \mathrm{~mm}$ thick plaques. The plaques were cured at $120^{\circ} \mathrm{C}$ for $4 \mathrm{~h}$ and at $160^{\circ} \mathrm{C}$ for $24 \mathrm{~h}$.

In the second method, the curing agent and the accelerator were mixed with the PBT-epoxy dispersion at room temperature. This mixture was then degassed under vacuum and poured into a mould that had been preheated in an oven in the temperature range $185-190^{\circ} \mathrm{C}$. The filled mould was then placed for a short time in an oven at a selected temperature in the range $185-190^{\circ} \mathrm{C}$ before being removed and cooled to room temperature. The resulting plaque was physically, but not chemically, gelled, with roughly $50 \%$ of the PBT having crystallized [25]. Because the rapid crystallization that caused gelation arose from self-nucleation, this method is referred to as the selfnucleation method. The plaque was then reheated and cured at $120^{\circ} \mathrm{C}$ for $4 \mathrm{~h}$ and at $160^{\circ} \mathrm{C}$ for $24 \mathrm{~h}$.

\subsection{Mechanical testing}

The fracture toughness was evaluated primarily using the double-torsion test, although some materials were also evaluated using three-point-bend testing. For double-torsion testing, specimens were cut from the cured plaques, and grooves were inserted on the underside with a small table saw. The depth of the groove was approximately one-half that of the specimen thickness. One end of each specimen was notched with a diamond saw and a precrack was inserted by tapping a chilled razor blade into the notch. The starter crack was always longer than 0.55 times the specimen width to minimize end effects. Four doubletorsion specimens were made from each plaque of material.

The fracture toughness was determined on an Instron 1137 mechanical testing machine. A crosshead displacement rate of $2.54 \mathrm{~mm} \mathrm{~min}^{-1}$ was used. Load-deflection curves were recorded on an $x-y$ plotter. The load-deflection curves were linear, and their behaviour was indicative of unstable or stick-slip crack propagation. The maximum in the load displacement curves was used to determine the crack-initiation fracture toughness from [26]

$$
K_{\mathrm{Ic}}=P W_{n}\left(\frac{3(1+v)}{w t^{3} t_{n}}\right)^{1 / 2}
$$


where $P$ is the maximum load, $W_{n}$ is the moment arm (the separation between the loading and support points of each arm), $v$ is Poisson's ratio, $w$ is the specimen width, $t$ is the specimen thickness and $t_{n}$ is the specimen thickness in the plane of the groove. Young and Beaumont have suggested that Equation 1 slightly underestimates the fracture toughness when $W / 2 t_{n}<10$, as is often the case, and they offered a correction in [27]. But their correction was not used.

Questions concerning the validity of the doubletorsion test have arisen recently. For example, Ricco et al. reported that the double-torsion test gave fracture-energy values that depended on the specimen thickness, with thicker specimens giving larger values [28]. The specimens used in the present study were, however, at the lower end of the thickness range considered by Ricco et al., where the fracture energies approximately coincided with those measured by other methods. Also, the present specimens were less tough and more stiff than those of Ricco et al., which is expected to reduce even further the errors of the type they reported. To confirm this, the fracture toughness of our toughest material was measured using a threepoint-bend geometry. A span length, $s$, of $50.8 \mathrm{~mm}$ was used, and cracks of depth $a$ were inserted by notching with a chilled razor blade. A displacement rate of $2.54 \mathrm{~mm} \mathrm{~min}^{-2}$ was used to test the specimens. The fracture toughness was evaluated using [26]

$$
\begin{aligned}
K_{\mathrm{Ic}}= & \frac{P S}{b w^{1 / 2}}\left[2.9\left(\frac{a}{w}\right)^{1 / 2}-4.6\left(\frac{a}{w}\right)^{3 / 2}\right. \\
& +21.8\left(\frac{a}{w}\right)^{5 / 2}-37.6\left(\frac{a}{w}\right)^{7 / 2} \\
& \left.+38.7\left(\frac{a}{w}\right)^{9 / 2}\right]
\end{aligned}
$$

where $a$ is the initial crack length, $w$ is the specimen width, $b$ is the specimen thickness, and $P$ is the maximum applied load.

For both double-torsion and three-point-bend specimens, the fracture energy, $G_{\text {Ic }}$, was calculated using

$$
G_{\mathrm{lc}}=\frac{K_{\mathrm{Ic}}^{2}}{E}
$$

where $E$ was the elastic modulus measured in compression.

Compressive yield strengths and moduli were measured on cylindrical specimens processed in the same manner as the plaques. Specimens with height-todiameter ratios of $2: 1$ were used, and the ends were lubricated with $\mathrm{MoS}_{2}$. A crosshead displacement rate of $2.54 \mathrm{~mm} \mathrm{~min}^{-1}$ was used to determine these properties.

\subsection{Characterization}

The glass-transition temperature of the epoxy and the melting temperature of the PBT were measured using differential scanning calorimetry (DSC) (Perkin Elmer DSC7). The DSC was calibrated with indium, and all the experiments were carried out under nitrogen. A heating rate of $20^{\circ} \mathrm{Cmin}^{-1}$ was used. The morpho- logy of the specimens was examined in thin films using an Olympus BH-2 polarizing optical microscope equipped with a Mettler-FP-82 hot stage.

The fracture surfaces were examined by scanning electron microscopy (SEM, Hitachi S-800). The fracture surfaces were sputtered with a thin layer of an $\mathrm{Au}-\mathrm{Pd}$ alloy before the examination. Stereo micrographs were taken by tilting the stage $8^{\circ}$ from horizontal to observe the topology of the surface.

\section{Results}

\subsection{PBT-epoxy morphologies}

The properties of the cured PBT-epoxy blends were found to depend on their morphology. Three types of morphology were found, and these are denoted as spherulitic dispersion, structureless gel and gel with spherulites. The type of morphology which occurred depended on the processing history of the blend.

An example of the spherulitic dispersion is shown in the optical micrograph in Fig. 2, which was obtained from a thin film between crossed polarizing filters. This specimen had been prepared by heating a mixture of PBT in the uncured epoxy to $220^{\circ} \mathrm{C}$ and then, after complete dissolution, allowing the mixture to crystallize at $155^{\circ} \mathrm{C}$. Following this, the epoxy was cured. The bright particles are PBT spherulites. In a thin film, the particles tended to agglomerate, but in bulk specimens they were well dispersed, as was also seen in the fracture surface micrographs. After crystallization, but before curing, this material was a liquid with a viscosity only slightly greater than that of the epoxy alone.

An example of the structureless gel is shown in the optical micrograph obtained with crossed polarizing filters in Fig. 3. This specimen had been prepared by pouring some of the spherulitic dispersion into a mould which was preheated to $185^{\circ} \mathrm{C}$ and the mixture and the mould were then placed in a $185^{\circ} \mathrm{C}$ oven for 5 min. After this, the mixture and the mould were cooled to room temperature and then heated to 120 and $160^{\circ} \mathrm{C}$ to cure and postcure the epoxy. Only a fine-grained or modulated background birefringence

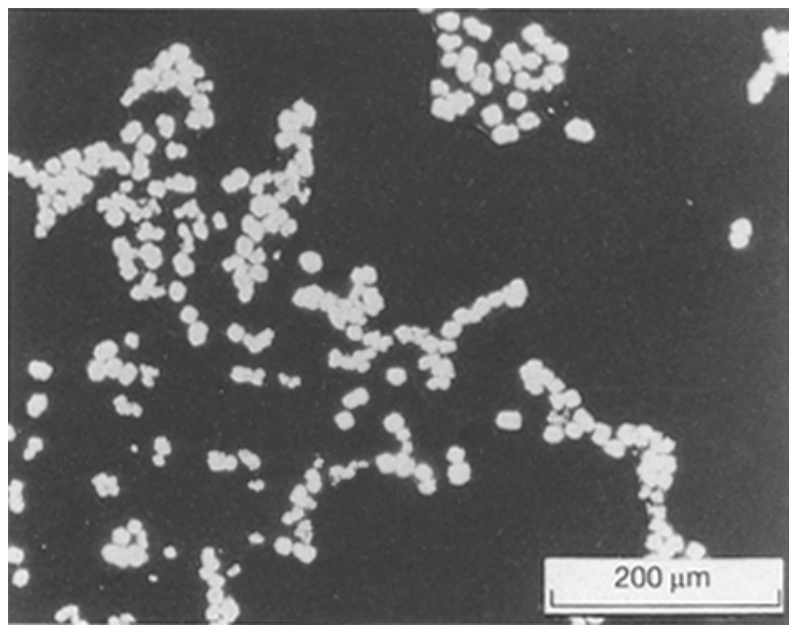

Figure 2 An optical micrograph of a cured 5\% PBT spherulitic blend taken under crossed polarizing filters. 


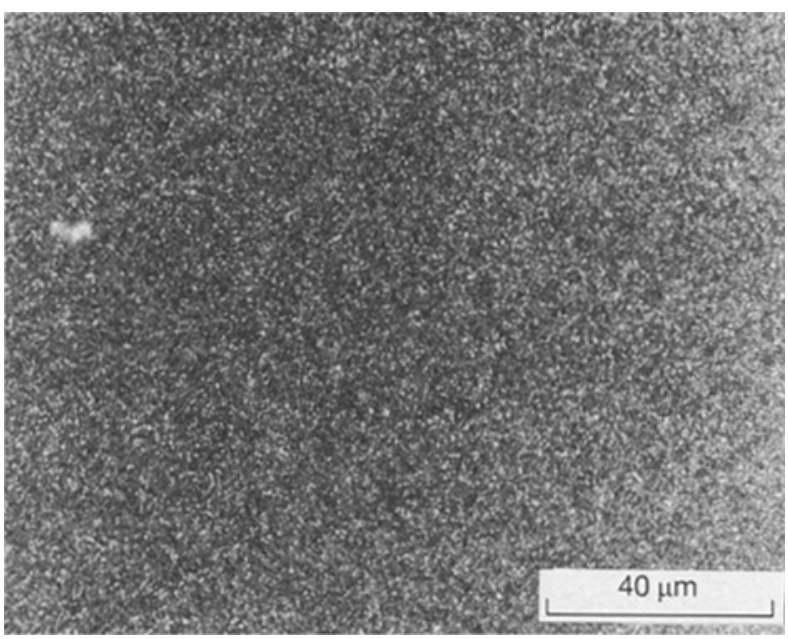

Figure 3 An optical micrograph of a cured 5\% PBT structureless gel taken under crossed polarizing filters.

with some very small points of light was seen. The material in thin films is transparent. This morphology is the same as that which was seen before curing [25]. Before curing, the mixture was a thermoreversible gel: it would not flow and it could support is own weight; but by heating it above $190^{\circ} \mathrm{C}$, a one-phase, lowviscosity, liquid solution could be recovered. In the cured state, these materials will be referred to as cured structureless gels. The formation of these gels was found to be very sensitive to small variations in the accelerator concentration, in the sample size, and in the temperatures and times during processing.

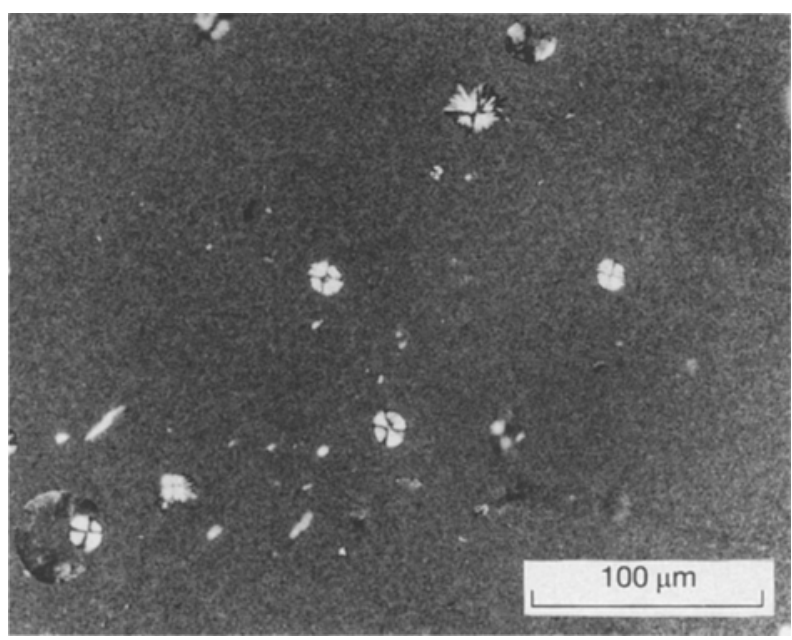

Figure 4 An optical micrograph of a cured $5 \%$ PBT gel with spherulitic inclusions taken under crossed polarizing filters.
An example of the gel with spherulites is shown in the optical micrograph obtained with crossed polarizing filters in Fig. 4. This specimen had been prepared by briefly heating some of the spherulitic dispersion to $190^{\circ} \mathrm{C}$ before cooling and curing. This morphology is a mixture of background birefringence and spherulites. This material was also a thermoreversible gel and it displayed no flow before curing. In the cured state, these materials will be referred to as cured gels with spherulites.

\subsection{Thermal and mechanical behaviour of PBT-epoxy blends}

Thermal analysis was performed on each of the cured blends. The PBT in each blend melted at approximately $225^{\circ} \mathrm{C}$ : the melting temperature of PBT in the pure state. The glass-transition temperature, $T_{\mathrm{g}}$, of the epoxy depended slightly on the morphology, varying from 162 to $165^{\circ} \mathrm{C}$ (see Table I). The glass-transition temperature of the cured epoxy without PBT was $170^{\circ} \mathrm{C}$.

The elastic modulus and the yield stress measured in compression are nearly the same for all the morphologies, and they are essentially equal to the values for the epoxy resin without PBT (see Table I).

The fracture toughness, $K_{\text {Ic }}$, and the fracture energy, $G_{\text {le }}$, measured by double torsion for the three morphologies with $5 \%$ PBT are also given in Table I. They can be seen to increase with the gel content. This increase can be substantial, with the fracture energy for the cured structureless gel $\left(2000 \mathrm{~J} \mathrm{~m}^{-2}\right)$ being more than ten times greater than that of the epoxy without PBT $\left(180 \mathrm{~J} \mathrm{~m}^{-2}\right)$. The dispersed spherulitic blends showed only a marginal improvement in the fracture toughness $\left(240 \mathrm{~J} \mathrm{~m}^{-2}\right)$, however, and the gel containing some spherulites had a toughness that was intermediate between these two values $\left(1150 \mathrm{~J} \mathrm{~m}^{-2}\right)$.

The variation in the fracture-energy measurements was small. The average fracture energy from different double-torsion specimens of the cured structureless gel ranged from 1800 to $2200 \mathrm{~J} \mathrm{~m}^{-2}$. The variation of the fracture energy within a single double-torsion specimen of the cured structureless gel was approximately $\pm 10 \%$. Also, the average fracture energy of the cured structureless gel measured by three-point bending was again $2000 \mathrm{~J} \mathrm{~m}^{-2}$.

\subsection{Fracture surface morphology}

To aid in elucidating the toughening mechanisms, the fracture surfaces were examined by SEM. A surface typical of the fast fracture of a 5\% PBT-epoxy blend

TABLE I The mechanical properties of 5\% PBT-anhydride-cured epoxy blends

\begin{tabular}{llllll}
\hline Material & $\begin{array}{l}T_{\mathrm{g}} \\
\left({ }^{\circ} \mathrm{C}\right)\end{array}$ & $\begin{array}{l}\text { Modulus stress } \\
(\mathrm{GPa})\end{array}$ & $\begin{array}{l}\text { Yield stress } \\
(\mathrm{MPa})\end{array}$ & $\begin{array}{l}K_{\mathrm{Ic}} \\
\left(\mathrm{MPa} \mathrm{m} \mathbf{m}^{1 / 2}\right)\end{array}$ & $\begin{array}{l}G_{\mathrm{Ic}} \\
\left(\mathrm{J} \mathrm{m}^{-2}\right)\end{array}$ \\
\hline Epoxy without PBT & 170 & 2.9 & 115 & 0.72 & 180 \\
Spherulitic dispersion & 165 & 2.9 & 113 & 0.83 & 240 \\
Gel with spherulites & 163 & 2.8 & 118 & 1.8 & 1150 \\
Structureless gel & 162 & 2.8 & 115 & 2.3 & 2000 \\
\hline
\end{tabular}


with a spherulitic dispersion morphology is shown in Fig. 5. The crack grew roughly from right to left. The bright circular or near-circular regions are individual spherulites. Each spherulite has a bifurcation line

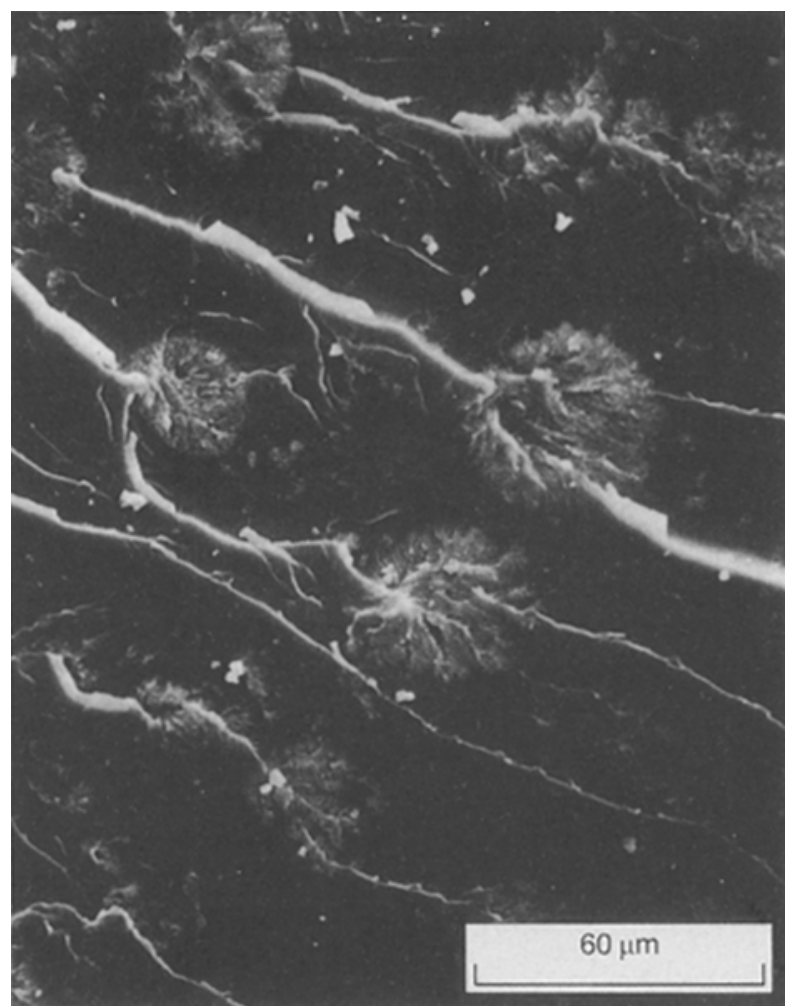

Figure 5 A scanning electron micrograph of a $5 \%$ PBT spheruliticblend fracture surface. Note the secondary cracks running through, or emanating from, each spherulite.

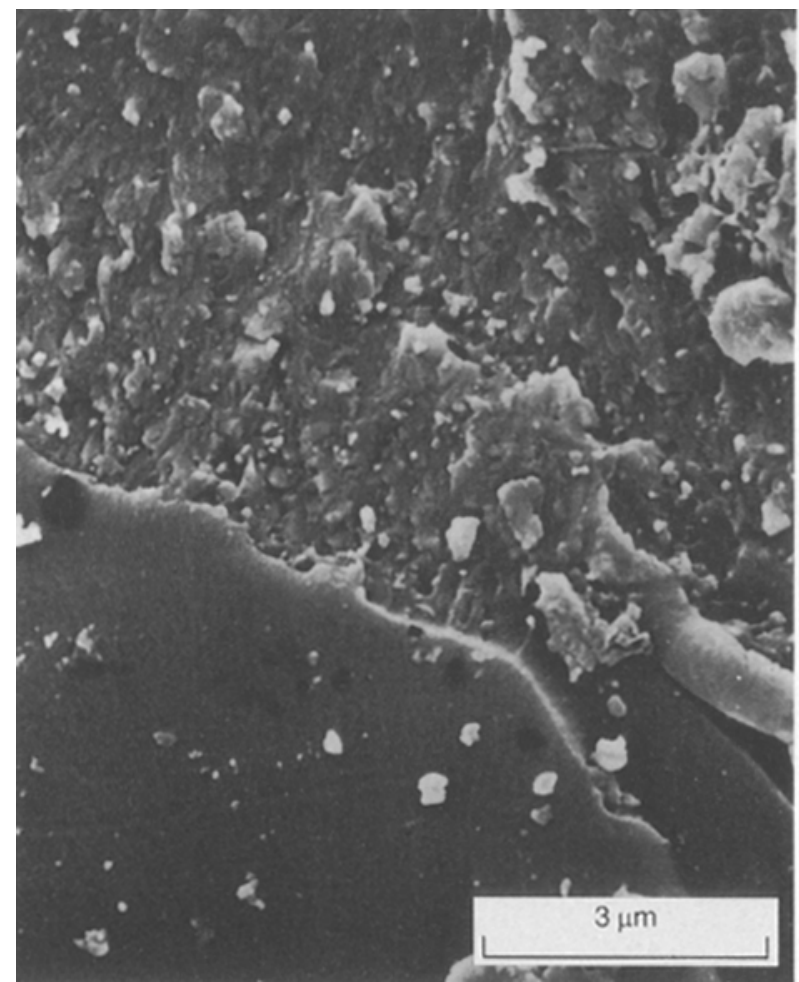

Figure $6 \mathrm{~A}$ high-magnification SEM micrograph of spheruliteepoxy interfacial region. (The spherulite is in the upper region and the epoxy is in the lower region.) emanating from it, consisting of a step and a welt. Such lines tend to retard crack growth. But otherwise, very little deformation of the matrix between the spherulites can be observed. The interface between the spherulite and the epoxy matrix is shown at a higher magnification in Fig. 6. The fracture progressed from the matrix to the spherulite with only a slight diversion of the crack at the boundary. Although the fracture surface inside the spherulite is much rougher than in the surrounding epoxy matrix, the two average surfaces are at approximately the same elevation. A pair of bifurcation lines are also visible in the lower right-hand side of Fig. 6; a detached welt is associated with the upper of the two lines. The step heights at the bifurcation lines tend to be modest. The detached welt suggests that the step height of the upper bifurcation line, which is the larger of the two, is about $1 \mu \mathrm{m}$.

A fracture surface of the cured structureless gel resulting from slow crack growth in three-point bending is shown in Fig. 7. The surface displays many features which are not seen on the fracture surfaces of unmodified epoxies or of epoxies containing a dispersion of spherulites. One of the more striking features is the large number of small holes that are present on the surface. These holes are present in both fast- and slowfracture regions. These holes can also be seen at high magnification in Fig. 8. The vertical relief around the holes becomes apparent when the micrographs are viewed as a stereo pair. The material was drawn above the surface around each hole for a distance equal to approximately two hole diameters. The appearance is like that of a volcano. Only raised holes have been observed; depression on the opposite fracture surface

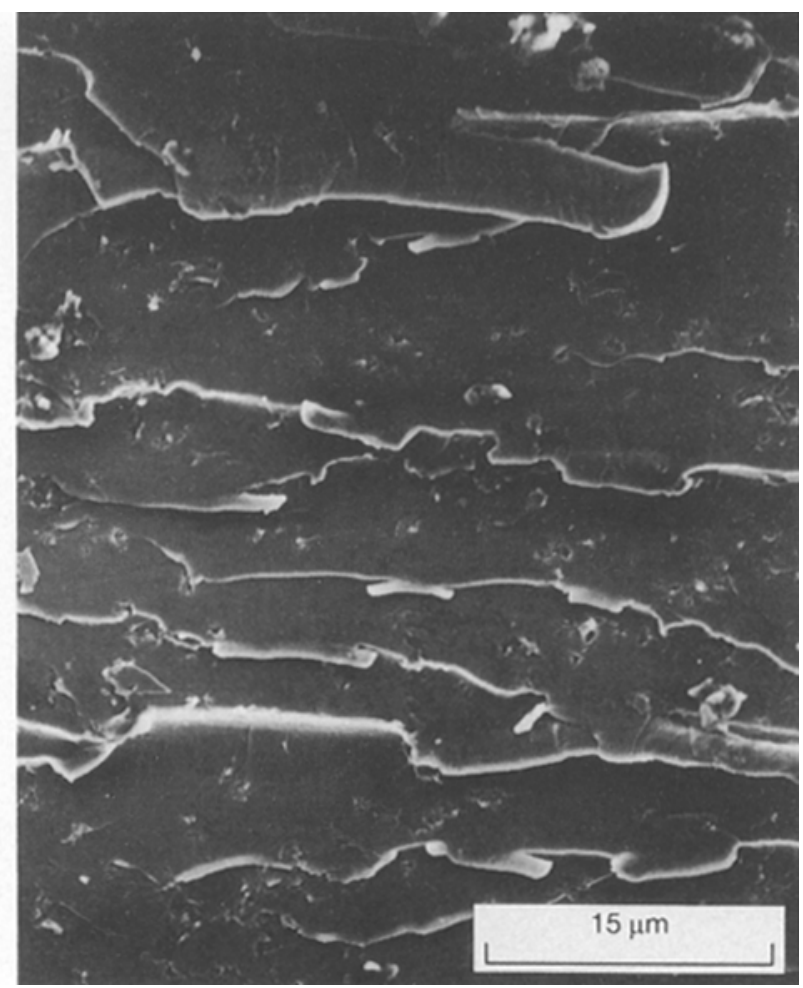

Figure 7 A SEM micrograph of the fracture surface in the slowcrack-growth region of a gelled blend. Note the large number of secondary cracks and the abundance of small holes. 


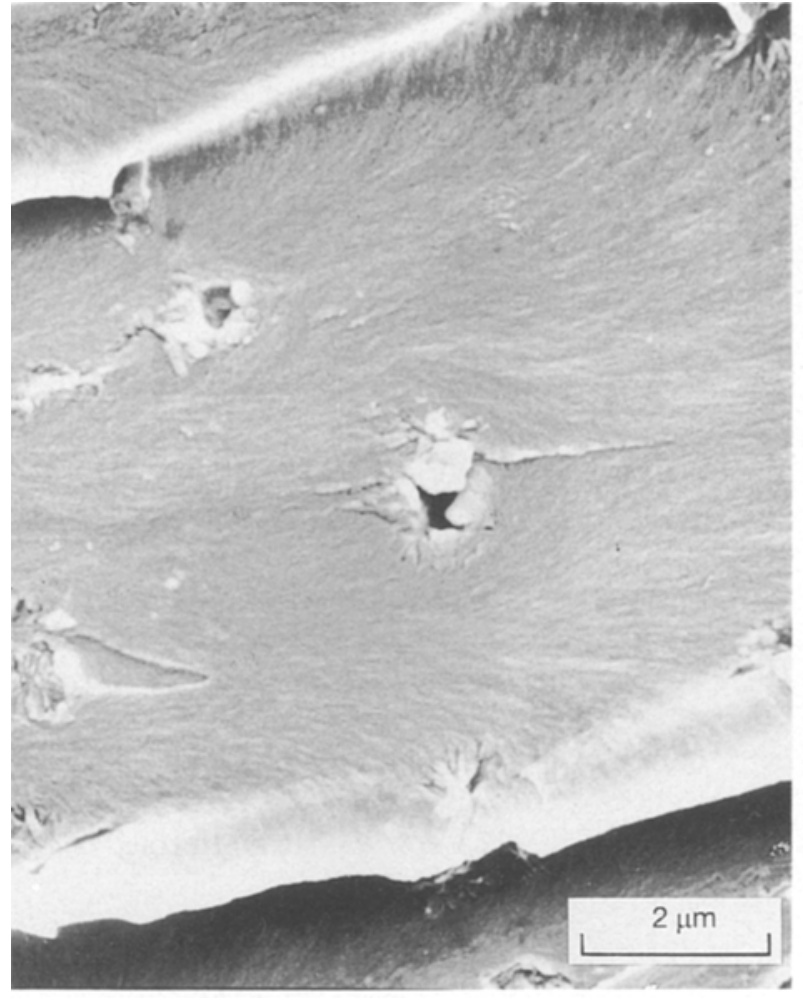

Figure 8 A high magnification micrograph of two small holes on the fracture surface of a 5\% PBT gelled blend. In stereo, the material is seen to be raised above the surface. Note the basic-longitudinaltexture divergence around the hole.

from which they might have been carved have not been seen. Observations of specimens sectioned with a diamond saw suggest that the holes are more or less perpendicular to the surface with no channeling between them. Often a smaller hole which extends deeper into the material is visible inside the surface hole. Several of these holes can be seen in Fig. 9.

Unlike the fracture surfaces of unmodified epoxies, or of epoxies containing a dispersion of spherulites, an abundance of plastic deformation is visible on the fracture surface of the cured structureless gels. In addition to the raised holes, plastic deformation is visible at the centre-right of Fig. 10, where small fingers can be seen projecting from the surface. These protuberances often appear near holes. The fingers are present in both the slow- and the fast-crack-growth regions, but they are more abundant in the slowcrack-growth regions.

A further feature of the cured structureless gels is the large number of bifurcated cracks present and the nature of these cracks. In the spherulitic-dispersion blend, each bifurcated crack was associated with a spherulite (Fig. 5). In the cured gel of Fig. 7, however, there are many crack-bifurcation lines which seem to have arisen either from holes or spontaneously. The step height between the cracks is fairly large, as indicated by the width of the welts, and the bifurcation lines seem to change direction frequently and erratically.

The fracture surface of the cured gels with included spherulites displayed features common to both the spherulitic blends and the cured structureless gels.

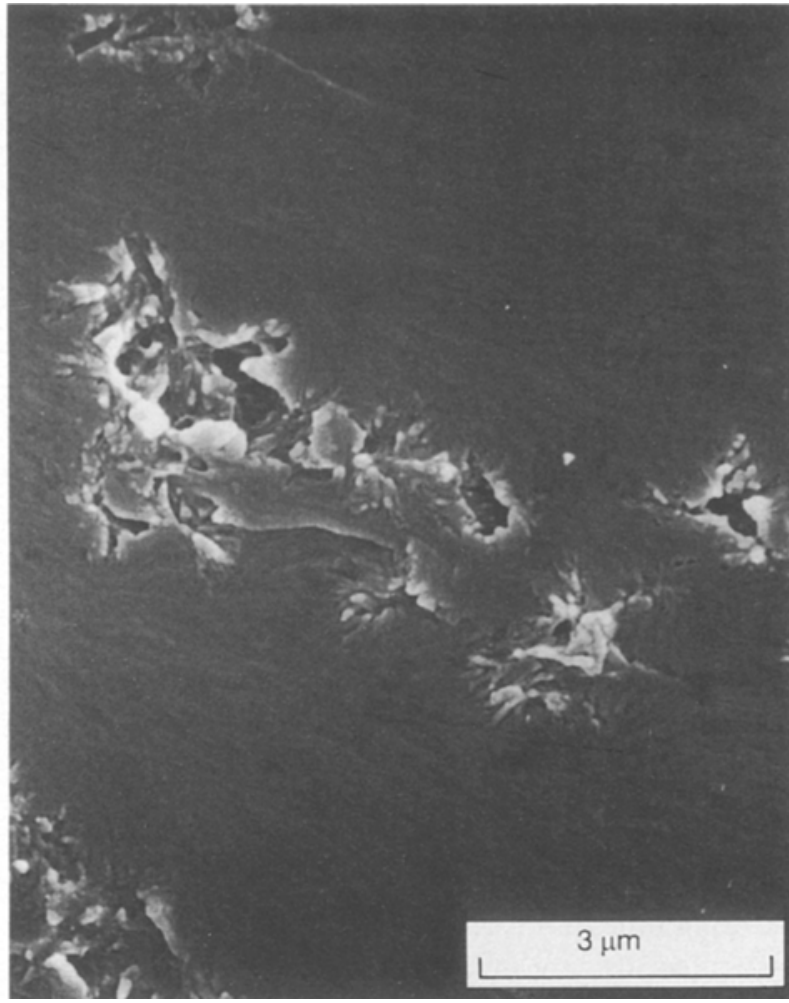

Figure 9 A SEM micrograph of a gelled-blend fracture surface showing a large bole with smaller holes visible in the lower-left corner of the large hole extending farther into the material.

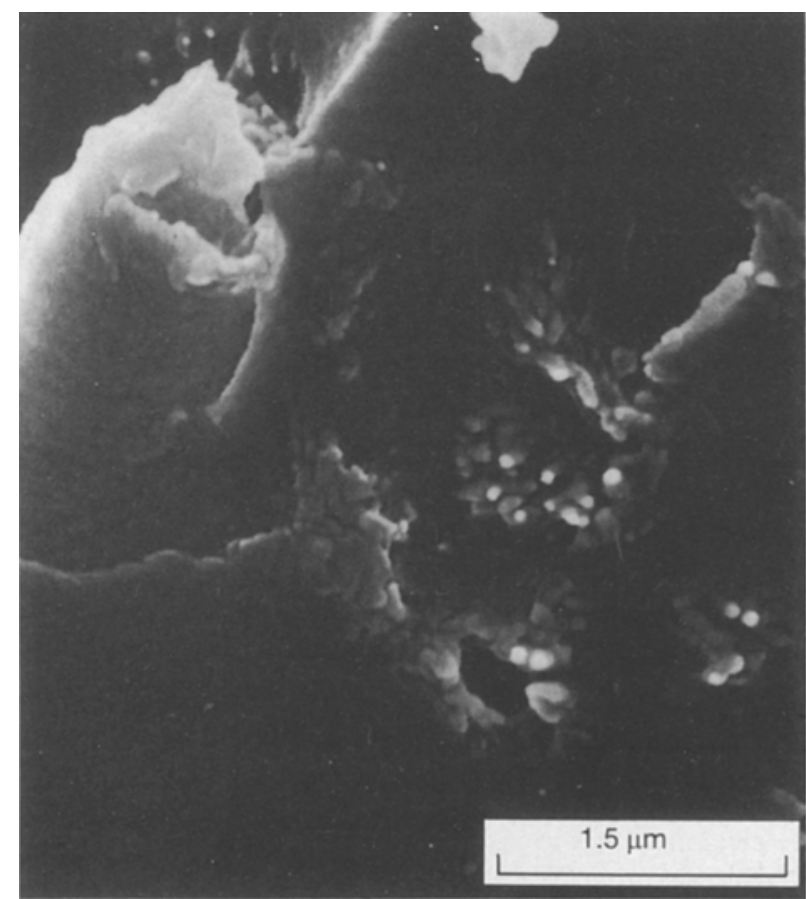

Figure 10 A SEM micrograph of fingers projecting from the fracture surface in the slow-crack-growth region of the PBT-epoxy gelled blend.

\section{Discussion}

The results presented here demonstrate that it is possible to greatly change the fracture toughness of PBT-epoxy blends by changing the PBT morphology. 
At one extreme, materials are composed of well-formed, isolated spherulites (Fig. 2). These materials show little increase in fracture energy above the energy of the unmodified epoxy. At the other morphological extreme, some materials display only a weak background birefringence when they are examined with a polarizing optical microscope, although the PBT is still estimated to be about $50 \%$ crystalline (Fig. 3 ). The fracture energy of these materials is increased by over an order of magnitude above that of the unmodified epoxy. Before examining in detail the fracture process and the toughening mechanisms, a brief review of the curing and morphological evolution of each of the materials is necessary.

\subsection{Preparation of cured PBT-epoxy blends}

For the uncured state, four different morphologies were found $[24,25]$ : spherulitic dispersion, spherulitic gel, structureless gel and gels with spherulites. Only three of these could be prepared in a cured state. A cured spherulitic gel could not be prepared because the long time that is required for crystallization allows the epoxy to cure first.

It has been suggested that the spherulitic-dispersion morphology is formed by liquid-liquid phase separation and subsequent crystallization of the PBT [24]. Because the spherulitic dispersion has a low viscosity, the curing agent was easily mixed with the PBT-epoxy blend, and curing was undertaken in a conventional manner.

The structureless gels were formed by the rapid crystallization of the PBT after the solution had been self-nucleated with PBT nuclei. This was accomplished by briefly heating a dispersion of PBT in epoxy to just above the dissolution temperature of PBT. With an exceptionally high nucleation density, the PBT quickly crystallized on cooling. This resulted in a microstructure consisting of small PBT crystallites linked together by PBT molecules or bundles of molecules; this microstructure has been proposed for other thermoreversible gels [29-36]. The small crystallites act as nodes or junction points for a PBT network. Due to their small size (less than $0.1 \mu \mathrm{m}$ ), individual nodes are not observable using an optical microscope and only a weak background birefringence resulted when the gels were viewed between crossed polar filters.

Gels with spherulites were formed in a similar manner to the structureless gels, except that the dispersion of PBT in epoxy was heated to a higher temperature, which melted more of the crystals. Hence, having a lower nuclei density, some spherulites also grew when the mixture was cooled.

Preparation of cured structureless gels and cured gels with spherulites was more difficult than the preparation of the cured spherulitic dispersion. A method of curing without destroying the morphology was required, which meant that all of the ingredients (the epoxy, the PBT, the curing agent and the accelerator) had to be mixed together before the gels were formed. But the system had to react sufficiently slowly that the thermal treatment necessary to effect physical gelation by the PBT could be performed before chemical gelation of the epoxy occurred. Also, the various ingredients had to be mutually compatible. An anhydride curing agent with a low concentration of imidazole accelerator was found to give satisfactory results, although the amount of accelerator and the times and temperatures needed to effect physical gelation by the PBT had to be tightly controlled to achieve reproducibility.

In some respects the gelled blends of PBT and epoxy are similar to interpenetrating networks (IPNs) [37-39]. Semi-IPNs, in particular, are formed by mixing a monomer with a linear polymer and polymerizing the monomer around the polymer. Macroscopically, these materials have one phase; but they show segregation on size scales of $100 \mathrm{~mm}$ or less. The difference between the PBT-epoxy system and semiIPNs is that PBT is highly crystallizable, but neither polymer is usually crystallizable in IPNs. Thus, an extra degree of morphological control and molecular organization is available in the PBT-epoxy system. Also, the gel in the PBT epoxy system is formed before the monomer is polymerized.

\subsection{Fracture-surface characteristics}

The fracture surfaces mirror the large difference in fracture energy between the cured structureless gels and the unmodified epoxies and epoxies containing dispersions of spherulites. Additional features appear on the fracture surfaces of the cured structureless gels which are not present on the fracture surfaces of other epoxy materials.

The most striking additional feature is the abundance of raised holes, looking like small volcanoes, that cover the fracture surface of the cured structureless gels. The fact that only mounds raised above the fracture surface are seen, and no depressions are seen, suggests that subsurface plastic deformation has occurred, allowing the mounds to be drawn above the surface in pairs, one on each side of the crack. The average separation between centres of the raised holes in Figs $7-10$ is about $3 \mu \mathrm{m}$. This distance is probably related to an uneven distribution of PBT, arising from the degree of dispersion of PBT in the epoxy before the mixture was heated and cooled to induce self-nucleated crystallization and gel formation.

The raised holes probably arose in the following way. When the crack approached regions of high PBT concentration, the crack probably tended to go around them, thus leaving roughly circular regions that continued to link the fracture surfaces together. Then, as the crack front moved on, and while the fracture stress continued to be applied, the linked regions behind the crack front plastically deformed. This allowed the surrounding crack to thicken and to spread into the linked regions, cutting the link. With complete separation, then, these regions look like mounds pulled above the surface.

This hypothesis for the formation of the mounds is supported by the basic longitudinal texture (BLT) on the fracture surface, which is a useful indicator of the local-crack-propagation direction. The BLT is the series of low ridges and shallow grooves present on the 
fracture surfaces of brittle network polymers, and it tends to be exactly parallel with the local direction of crack growth $[40,41]$. The BLT looks like flow lines on the surface (in Fig. 8, for example) and they can be seen to diverge around the central hole. That is, the BLT shows that locally the crack made a wide sweep around the area where the hole will form, and only later did the crack grow into this area, presumably leaving mounds on both fracture surfaces with a hole in each. This same behaviour of the BLT was found for all the holes which were examined. (See Figs 9 and 10 also).

It is likely that the holes began as a debonding between the PBT and the epoxy. Since the roughly cylindrically shaped material drawn from the fracture surfaces would be under a large triaxial stress, the PBT inside the cylinder could be forced to debond from the surrounding epoxy. With subsequent stretching of the surrounding epoxy, the hole would have enlarged, so that when the cylinder of material finally fractured, a hole approaching $1 \mu \mathrm{m}$ in diameter would have developed. Most of the holes seem to be partly closed, presumably because of the epoxy and/or the PBT that snapped back after fracturing. The small hole at the bottom of the larger holes indicates the considerable distance below the fracture surface that was involved in the formation of the mounds.

Another striking feature on the fracture surfaces of the cured gels is the multitude of crack bifurcations. In the cured spherulitic dispersion blends, cracks bifurcated as they encountered each spherulite. In the cured structureless gels, being without spherulites, the cracks appear to have bifurcated either at holes or simply spontaneously. Also, the steps and welts, or perhaps an accumulation of parallel steps and welts, are larger in cured structureless gels than in the cured spherulitic blends, and the edges of the step are much more jagged.

The bifurcation of the crack and the accumulation of parallel steps and welts in cured structureless gels may arise from the similarity between the scale of heterogeneity and the periodicity of the fingered crack front. The front of a crack propagating through a brittle network polymer has been hypothesized to be in the shape of fingers projecting ahead of the crack $[40,41]$. This is suggested to occur by the liquefaction of the polymer under the high stress at the crack front and the subsequent instability of the meniscus separating the liquid from voids or air in the crack. The remains of this process become the BLT, which allows the width or periodicity of the fingers of the crack front to be estimated, and is of the order of $100 \mathrm{~nm}$ or smaller. Hence, the finger width would be a similar order of magnitude to the separation between the nodes in the gels or to the thickness of the crystal lamellae in the spherulites, but it would be much smaller than the size of the individual spherulites.

In the cured dispersed-spherulite blends, as the crack advances through the relatively homogeneous epoxy between the spherulites, individual fingers of the crack tip are rarely diverted from the average direction of the crack. But when the fingers reach a spherulite, the lamellae within the spherulite, interfere with and cause the fingers to undergo numerous individual redirections. (Due to the process by which they form, the spherulites are only about $30 \%$ PBT. The rest of the volume is occupied by the epoxy [24].) This causes a great deal of surface roughness inside the spherulite, as can be seen in Fig. 7.

In the cured structureless gels, concentrations of crystalline PBT nodes are probably spaced throughout the material with a periodicity that is somewhere between the $12 \mathrm{~nm}$ separation that has been estimated for a uniform distribution of crystalline nodes [25] and the $3 \mu \mathrm{m}$ separation between holes on fracture surfaces. This would make the spacing comparable in order of magnitude to the size of the crack fingers. Interactions between these node concentrations and the propagating crack front, then, can cause the paths of individual fingers to shift into different directions, and this results in crack bifurcation [42]. Since the sizes of the crack fingers and the concentrations of crystalline PBT nodes are generally smaller than the resolution in Fig. 7, bifurcation can appear to arise spontaneously.

\subsection{Toughening mechanisms}

A number of toughening mechanisms have been identified. These include crack bridging $[43,44]$, crack pinning by inclusions [45], which may be better expressed as crack-path altering and welt bridging [20], ductile fracture of inclusions, induced matrix plasticity [7], secondary fracturing, and phase transformation toughening [21]. Usually, several of these mechanisms are operational during fracture, and they can often be discerned by examination of the fracture-surface morphology.

For the dispersed-spherulite blend of 5\% PBT in epoxy, rough fracture surfaces within the spherulites (Fig. 6) and bifurcation tails in the epoxy matrix (Fig. 5) have been noted. The rough surface within the spherulites represents a small increase in the fracture surface. Some phase-transformation toughening, from a PBT phase change in a thin layer of the spherulites adjacent to the fracture plane, may also have occurred, although gross phase-transformation toughening does not occur with this blend $[21,22]$. The bifurcation tails result from crack-path altering and welt bridging. The welts have relatively small diameters, however, so that the energy absorbed by their being stretched between opposite fracture surfaces would be modest. The combination of these mechanisms represents an excess fracture energy (which is above the energy of the epoxy resin alone) of $60 \mathrm{~J} \mathrm{~m}^{-2}$; that is, about onethird of the fracture energy of the epoxy without PBT.

For the cured gel of 5\% PBT in epoxy, the fracture surfaces (Figs 7-10) indicate the occurrence of matrix plasticity, ductility of the PBT inclusions and crack bifurcation. The depth below the surface to which the matrix plasticity and the PBT ductility extend is uncertain, however. Attempts were made to determine this depth by transmission electron microscopy (TEM) of microtomed sections, but the electron-density contrast between PBT and the epoxy was not sufficient to observe the PBT nodes, for example; this 
could have indicated deformation of the PBT and surrounding matrix. Images from microtomed sections more than $10 \mu \mathrm{m}$ below the surface were uniformly grey. This at least indicated that the holes visible at the surface did not extend more than $10 \mu \mathrm{m}$, if that much, below the surface. The processes visible at the surface by themselves, however, are unable to explain more than a fraction of the very large "excess" fracture energy of this material. The excess fracture energy is about ten times that of the epoxy without PBT.

Considering only the matrix plasticity observed at the surface, the associated excess fracture energy can be estimated as follows. The holes account for approximately $3 \%$ of the surface area, but the holes and surrounding mounds account for almost $20 \%$ of the area. The mounds are raised by approximately $2 \mu \mathrm{m}$ above the surface. If the material is deformed below the mounds for twice this depth at the yield stress $(115 \mathrm{MPa})$ and to a strain of $100 \%$, then approximately $180 \mathrm{~J} \mathrm{~m}^{-2}$ would be associated with mound formation. Because the mounds are the last points of attachment behind the crack front, while they bridge the crack, they apply a traction to keep the crack closed, which is the toughening mechanism known as crack bridging $[43,44]$. Its contribution to the fracture energy is the value of $180 \mathrm{~J} \mathrm{~m}^{-2}$ already calculated.

To be able to estimate from other considerations how much deeper plastic deformation of the PBT and epoxy occur, the mechanism which is involved must be understood. Kim and Brown have suggested [15] that thermoplastic particles can induce plastic deformation and shear banding in epoxies by creating stress concentrations. This was deduced from observations of the behaviour of a resorcinol-based epoxy modified with a glassy oligomer. The stress concentration was suggested to arise because the inclusions yielded before the epoxy. This is similar to the mechanism by which rubber cavitation has been suggested to induce shear yielding in rubber-modified epoxies. The deformation of the rubber particles absorbs little energy, but it acts to trigger plasticity in the surrounding matrix, which does absorb energy $[6,7]$.

The concomitant degree of yielding induced in the surrounding matrix depends on the dispersion of the particles. Wu and Margolina have suggested that the critical parameter is the interparticle spacing [46-48]. This suggestion arose from observations of rubbermodified nylons, and further support for it was given by Pearson for rubber-modified epoxies [49]. Below a critical interparticle spacing the matrix was ductile, and above this critical spacing the matrix was not ductile; this result was independent of the particle size. The same interparticle spacing can be obtained from either small particles at low concentrations or from large particles at high concentration. Wu has explained the sensitivity to interparticle spacing by associating it with the state of stress. At large interparticle spacings, the state of the stress is plane strain and the material is brittle. At small interparticle spacings, the state of stress is plane stress and the material is ductile. The critical interparticle spacing occurs when the state of stress changes from being plane strain to being plane stress. The critical spacing is matrix dependent, and for more highly cross-linked, higher $T_{\mathrm{g}}$ matrices, the critical interparticle spacing is generally smaller. But the induction of matrix ductility, even if the interparticle spacing is smaller than the critical spacing, requires that the triaxial stress within the particles be relieved. For dispersed rubber particles, this generally occurs by cavitation. For some dispersed thermoplastic particles, this may occur by yielding, as suggested by Kim and Brown. But for PBT particles, a phase transformation can relieve the stress.

Under a tensile stress of about $70 \mathrm{MPa}$, entailing a strain of $9-10 \%$, PBT transforms from an $\alpha$ - form to a $\beta$-form [50]. In the $\alpha$-form, the butylene segment of PBT is generally thought to be in a helical conformation; in the $\beta$-form, the butylene segment is thought to be fully extended. The phase change involves a decrease in density from 1.40 to $1.28 \mathrm{Mg} \mathrm{m}^{-3}$ [51-55].

The stress distribution around the crack tip can be used to estimate the distance from the fracture plane where the PBT phase transformation could still be expected to occur. According to the stress analysis of a linear elastic body in the vicinity of a plane crack tip [56], the maximum principal stress, $\sigma_{1}$, existing a lateral distance $y$ from the fracture plane is

$$
\sigma_{1}=0.500 \frac{K_{\mathrm{I}}}{y^{1 / 2}}
$$

where $K_{1}$ is the stress intensity. Using the critical stress intensity in Table I for $K_{\mathrm{I}}$ for the anhydride-cured epoxy of this study without PBT (that is, $0.72 \mathrm{MPa} \mathrm{m}^{1 / 2}$ ), the maximum tensile stress is equal to or greater than the phase-transformation stress of PBT (that is, $70 \mathrm{MPa}$ ), for distances up to $26 \mu \mathrm{m}$ on each side of the crack plane. If the critical stress intensity for the cured structureless gel, $2.3 \mathrm{MPa} \mathrm{m}^{1 / 2}$, is used for $K_{\mathrm{I}}$ instead, the maximum tensile stress is equal to the phase transformation stress of PBT for distances up to $270 \mu \mathrm{m}$ on either side of the crack plane. For a fine particulate dispersion of PBT particles in an aromatic amine-cured epoxy with a fracture toughness of $1.48 \mathrm{MPa} \mathrm{m}^{1 / 2}$, deformation of the PBT particles was observed about $125 \mu \mathrm{m}$ from the fracture surface $[20,21]$. For this material, Equation 4 gives an approximate value of $110 \mu \mathrm{m}$ as the distance from the fracture plane where the maximum tensile stress falls to $70 \mathrm{MPa}$.

The energy absorbed by the network of PBT nodes in the cured gel because of the change in phase can be estimated as follows [21]. The energy absorption rate for the transformation of PBT from the $\alpha$-form to the $\beta$-form (under a stress of $70 \mathrm{MPa}$ inducing a $10 \%$ strain) is $7 \mathrm{MJ} \mathrm{m}^{-3}$. Assuming that the transformation zone is $0.25 \mathrm{~mm}$ thick $(125 \mu \mathrm{m}$ on either side of the crack plane) and that the PBT represents $5 \%$ of the volume, the contribution of the phase transformation to the fracture energy would be about $90 \mathrm{~J} \mathrm{~m}^{-2}$.

If the phase transformation of PBT were to trigger plastic deformation in the matrix, the energy absorbed could be much larger. Assuming a yield stress of $115 \mathrm{MPa}$ (from Table I) and a yield strain of about $100 \%$, the energy absorption rate is $115 \mathrm{MJ} \mathrm{m}^{-3}$. 
Again, with a transformation or process zone $0.25 \mathrm{~mm}$ thick and with the epoxy occupying $95 \%$ of the volume, matrix plasticity would contribute about $27300 \mathrm{~J} \mathrm{~m}^{-2}$ to the fracture energy.

These estimates allow several conclusions to be made. First, the dispersed PBT has probably been able to undergo phase transformation within a large region extending well away from the fracture surfaces. This phase transformation involves an expansion that can respond to the approximately triaxial tensile-stress field, and the field is of sufficiently high strength to effect the transformation. Second, since the phase transformation itself would add only about $100 \mathrm{~J} \mathrm{~m}^{-2}$ to the fracture energy, the transformation appears to have triggered deformation of the surrounding matrix. Third, the matrix deformation is probably short of yielding, except at the fracture surface. The deformation is probably a combination of elastic and anelastic strains, with a total strain of around $10 \%$. A total matrix strain of $11 \%$ in a region $0.25 \mathrm{~mm}$ thick about the fracture surface would account for the otherwise unaccountable fracture energy of about $1500 \mathrm{~J} \mathrm{~m}^{-2}$, if the anelastic strain were one-third of the total strain.

\section{Conclusion}

A method was found by which $5 \%$ of a thermoplastic PBT, was able to increase the fracture energy, $G_{\text {Ic }}$, of a brittle anhydride-cured epoxy from 180 to $2000 \mathrm{~J} \mathrm{~m}^{-2}$. This increase essentially did not change the elastic modulus or the yield strength of the epoxy and there was only a small reduction in the glass-transition temperature of the epoxy from 170 to $162^{\circ} \mathrm{C}$. The method involved controlling the PBT morphology. By changing from a dispersion of isolated spherulites to a gel network, the fracture energy of the anhydridecured epoxy containing 5\% PBT was increased from 240 to $2000 \mathrm{~J} \mathrm{~m}^{-2}$. This same change in the morphology is expected to have a similar salutary effect on the toughness of dispersions in epoxy of other thermoplastics. Although other thermoplastics may respond differently to stress than PBT (by yielding as the phase changes for example), the effect on the surrounding matrix is expected to be similar and the effect on toughness comparable. The morphological change was affected using a crystalline thermoplastic that was soluble in the liquid epoxy and that was able to crystallize into a thermoreversible gel by self-nucleation. Thermoreversible gels have been made in other ways from non-crystalline polymers, and these ways may also be effective tougheners for brittle-matrix resins.

\section{Acknowledgements}

The authors would like to thank Dr Junkyung Kim for his assistance at the beginning of this work and Dr Albert F. Yee for useful comments. The work was supported in part by the National Science Foundation through a Materials Research Group grant, DMR8708405 , and in part by NIDR Specialized Materials Science Research Center Grant DE-09296.

\section{References}

1. J. N. SUltan and F. J. McGarky, J. Polym. Sci., Polym. Phys. Ed. 13 (1973) 29.

2. C. B. BUCKNALL, "Toughened plastics" (Applied Science, London, 1977).

3. W. D. BASCOM, R. Y. TING, R. J. MOULTON, C. K. RIEW and A. R. SIEBERT, J. Mater. Sci. 16 (1981) 2657.

4. A. J. KINLOCH, S. J. SHAW, D. A. TOD and D. L. HUNSTON, Polymer 24 (1983) 1341.

5. A. F. YEE and R. A. PEARSON, J. Mater. Sci. 21 (1986) 2462.

6. R. A. PEARSON and A. F. YEE, ibid. 21 (1986) 2475.

7. Idem., ibid. 24 (1989) 2571.

8. A. C. GARG and Y.-W. MAI, Compos. Sci. Technol. 31 (1988) 179.

9. W. B. CHERRY and K. W. THOMPSON, J. Mater. Sci. 16 (1981) 1913.

10. T. D. CHANG and J. O. BRITTAIN, Polym. Engng. Sci. 22 (1982) 1228 .

11. C. B. BUCKNALL and I. K. PARTRIDGE, Polymer 24 (1983) 639.

12. J. L. HEDRICK, I. YILGOR, G. L. WILKES and J. E. McGRATH, Polym. Bull. 13 (1985) 201.

13. C. B. BUCKNALL and I. K. PARTRIDGE, Polym. Engng. Sci. 26 (1986) 54.

14. R. S. RAGHAVA, J. Polym. Sci., Polym. Phys. Ed. 25 (1987) 1017.

15. S. C. KIM and H. R. BROWN, J. Mater. Sci. 22 (1987) 2589.

16. R. S. RAGHAva, J. Polym. Sci., Polym. Phys. Ed. 26(1988) 65.

17. C. B. BUCKNALL and A. H. GILBERT, Polymer 30 (1989) 213.

18. J. L. HEDRICK, I. YILGOR, M. JUREK, J. C. HEDRICK, G. L. WILKES and J. E. McGRATH, Polymer 32 (1991) 2020.

19. G. S. BENNETT, R. J. FARRIS and S. A. THOMPSON, ibid. 32 (1991) 1633.

20. J. K. KIM and R. E. ROBERTSON, J. Mater. Sci. 27 (1992) 161.

21. Idem., ibid. 27 (1992) 3000.

22. Idem., in "Toughened plastics I", edited by C. K. Riew and A. J. Kinloch (American Chemical Society, Washington, DC, 1993) pp. 427-49.

23. W. N. KIM and L. M. BURNS, Makromol. Chem. 190 (1988) 661.

24. M. E. NICHOLS and R. E. ROBERTSON, J. Polym. Sci., Polym. Phys. Ed. 32 (1994) 573.

25. Idem., ibid. 32 (1994) 1607.

26. A. J. KINLOCH and R. J. YOUNG, "Fracture behaviour of polymers" (Elsevier, London, 1983).

27. R. J. YOUNG and P. W. R. BEAUMONT, J. Mater. Sci. 12 (1977) 684.

28. T. RICCO, R. FRASSINE and A. PAVAN, ibid. 25 (1990) 1517.

29. A. TAKAHASHI, T. NAKAMURA and I. KAGAWA, Polym. J. 3 (1972) 207.

30. E. D. T. ATKINS, D. H. ISSAC, A. KELLER and K. MiYASAKA, J. Polym. Sci., Polym. Phys. Ed. 15 (1977) 211.

31. S. WELLINGHOFF, J, SHAW and E. BAER, Macromolecules 12 (1979) 932.

32. J.-M. GUENET, B. LOTZ and J.-C. WITTMANN, ibid. 18 (1985) 420.

33. R. C. DOMSZY, R. ALAMO, C. O. EDWARDS and L. MANDELKERN ibid. 19 (1986) 310.

34. J.-M. GUENET, ibid. 19 (1986) 1961.

35. W. STOKS, H. BERGHMANS, P. MOLDDENAERS and J. MEWIS, Brit. Polym. J. 20 (1988) 361.

36. J. H. AUBERT, Macromolecules 21 (1988) 3468.

37. K. H. HSIEH and J. L. HAN, J. Polym. Sci., Polym. Phys. Ed. 28 (1990) 623.

38. Idem., ibid. 28 (1990) 783.

39. H. XIAO, Z. H. PING, J. W. XIE and T. Y. YU, J. Polym. Sci., Polym. Chem. Ed. 28 (1990) 585.

40. R. E. ROBERTSON and V. E. MINDROIU, Polym. Engng. Sci. 27 (1987) 55.

41. J. S. COVAVISARUCH, R. E. ROBERTSON and F. E. FILISKO, J. Mater. Sci. 27 (1992) 990. 
42. R. E. ROBERTSON, V. E. MINDROIU and M.-F. CHEUNG, Compos. Sci. Technol. 22 (1985) 197.

43. S. KUNZ-DOUGLASS, P. W. R. BEAUMONT and M. F. ASHBY, J. Mater. Sci. 15 (1980) 1109.

44. L. F. R. ROSE, Mech. Mater. 8 (1987) 11.

45. F. F. LANGE and K. C. RADFORD, J. Mater, Sci. 6 (1971) 1197.

46. S. WU, J. Polym. Sci., Phys. Ed. 21 (1983) 699.

47. Idem., Polymer 26 (1985) 1855.

48. A. MARGOLINA and S. WU, ibid. 29 (1989) 2170.

49. R. A. PEARSON, PhD Thesis, The University of Michigan, Ann Arbor (1990).

50. K. TASHIRO, Y. NAKAI, M. KOBAYASHI and $H$ TADOKORO, Macromolecules 13 (1980) 137.

51. Z. MENCIK, J. Polym. Sci., Polym. Phys. Ed. 13 (1975) 2173.

52. I. M. HALL and M. G. PASS, Polymer 17 (1976) 807.
53. M. YOKOUCHI, Y. SAKAKIBARA, Y. CHATANI, H. TADOKORO, T. TANAKA and K. YODA, Macromolecules 9 (1976) 266.

54. B. STAMBAUGH, J. L. KOENIG and J. B. LANDO, $J$. Polym. Sci., Polym. Phys. Ed. 17 (1979) 1053.

55. B. STAMBAUGH, J. B. LANDO and J. L. KOENIG, ibid. 17 (1979) 1063

56. B. R. LAWN and T. R. WILSHAW, "Fracture of brittle solids" (Cambridge University Press, Cambridge, 1975) pp. $52-6$.

Received 5 August 1993

and accepted 10 May 1994 